\title{
Pengaruh Partikel Nanosilika Terhadap Sifat Tolak Air Bahan Isolasi Bionanokomposit
}

\author{
Aulia Aulia*, Roan Alfajri, Eka Putra Waldi, dan Novizon Novizon \\ Jurusan Teknik Elektro, Fakultas Teknik, Universitas Andalas, Padang, Sumatera Barat, Indonesia \\ *Corresponding author, e-mail: aulia@eng.unand.ac.id
}

\begin{abstract}
Abstrak - Sifat hidropobisitas memainkan peran penting dari sebuah isolator, terutama isolator pasang luar yang selalu terpapar oleh perubahan cuaca panas, dingin, lembab dan air hujan. Dalam jangka panjang, permukaan isolator bisa rusak dan sifat hidropobisitasnya akan berkurang bahkan hilang sehingga peristiwa peluahan permukaan akan lebih mudah terjadi, terutama pada musim hujan. Sebagai material baru yang sedang dikembangkan, bahan isolasi bionanokomposit dari polietilena berkerapatan rendah (LDPE), karet alam (NR) dan pengisi nanosilika telah melewati beberapa pengujian sifat dielektrik seperti karakteristik peluahan sebagian pada kondisi normal dan pada kondisi suhu yang lebih tinggi. Untuk melengkapi pengkajian sifat dielektrik, maka dilakukan pengujian sifat hidropobisitas bahan bionanokomposit yang baru tersebut. Sampel yang diuji ada 4 jenis dengan kada berat bahan nanosilika 1,5\%, 3,0\%, 4,5\% dan $6 \%$ dari berat total sampel biokomposit. Pengujian dilakukan dengan menggunakan kamera beresolusi tinggi untuk mengambil gambar permukaan sampel isolator yang ditetesi air. Hasil menunjukan bahwa nanosilika dapat memperbesar sudut kontak air dengan permukaan bionano komposit. Peningkatan ini mengindikasikan meningkatnya sifat hidropobisitas material bionanokomposit.
\end{abstract}

Kata Kunci : Biokomposit, Hidropobisitas, Karet Alam, LDPE

\begin{abstract}
The nature of hydropobicity plays an important role of an insulator, especially the outdoor insolator which is always exposed to hot, cold, humid weather and rain water. In the long run, the surface of the insulator can be damaged and its hydropobicity properties will be reduced or even lost so that surface discharge events will be easier to occur, especially in the rainy season. As a new material being developed, bionanocomposite insulation materials from LDPE, natural rubber and nanosilica fillers have passed several dielectric properties such as partial discharge characteristics under normal conditions and at higher temperature conditions. To complete the assessment of dielectric properties, a new bionanocomposite material hydropobicity was tested. There were 4 types of samples tested with the weight of the nanosilica material $1.5 \%, 3.0 \%, 4.5 \%$ and $6 \%$ of the total weight of the biocomposite sample. The test was carried out using a high-resolution camera to take pictures of the surface of the insulator sample that was dripped with water. The results show that nanosilica can increase the angle of contact of water with the bionanocomposite surface. This increase indicates an increase in the hydropobicity of bionanocomposite material.
\end{abstract}

Keywords : LDPE, Karet Alam, Natural Rubber, nanosilica, hydrophobisity

\section{Pendahuluan}

Untuk isolator pasang luar, sifat hidropobisitas atau sifat tolak air menjadi penting untuk dimiliki. Semakin tinggi sifat hidropobisitas maka semakin baik, sebaliknya jika sifat tolak air rendah maka isolasi tersebut tidak layak dipakai untuk isolator pasang luar $[1,2]$. Walaupun isolator polymer memiliki sifat dielektrik yang kuat, seiring perjalan waktu dan tingginya intensitas sinar ultraviolet yang menerpa permukaanmaka sifat tolak air akan menurun [3].

Sifat hidropobisitas yang tinggi akan memungkinkan permukaan isolator kering dengan cepat jika ditetesi oleh air dan membantu proses pembersihan permukaan isolator secara alamiah. Dengan demikian isolator yang memiliki sifat hidropbisitas tinggi akan memberikan keuntugnan ganda kepada PT.PLN sebagai pemilik sekaligus pengelola jaringan trasmisi dan distribusi listrik. Keuntungan pertama adalah meningkatkan kualitas daya yang disalurkan dengan mengurangi harmonisa dan arus bocor yang ditimbulkan isolator. Keuntungan kedua adalah berkurang biaya operasional pemeliharaan karena rentang waktu pembersihan menjadi lebih lama dan proses pembersihan akan lebih cepat. 
Sebagai material yang sedang dikembangkan, isolator dari bionanokomposit yang terbuat dari etilena berkeraptan rendah, karet alam [4] dan bahan pengisi nanosilika ( $\mathrm{SiO} 2)$ juga harus memiliki sifat hidropobisitas yang tinggi agar dapat diaplikasikan pada sistem kelistrikan khususnya untuk jaringan transmisi dan jaringan distribusi.

Pada penelitian terdahulu, kajian sifat dielektrik bionankomposit LDPE-NR- $\mathrm{SiO} 2$ selanjut akan disebut bionanokomposit saja, telah mengalami serangkaian kajian sifat mekanik $[5,6]$ dan dielektrik. Kajian sifat dielektrik memperlihatkan peningkatan ketahanan bahan terhadap peristiwa peluahan sebagaian pada bahan bionanokomposit $[7,8]$. Namun kajian tentang sifat hidropobisitas permukaan bionanokomposit LDPE-NR dan nanosilika belum banyak kajian yang dilakukan. Pada penelitian yang diajukan sekarang akan dilakukan kajian tersebut. Diperkirakan sifat hidropobis sampel tersebut juga akan meningkat.

\section{Isolator}

Isolator dipengaruhi oleh lingkungan seperti perubahan suhu, iklim, radiasi sinar matahari dan rentan dengan kondisi lingkungan yang dapat menyebabkan permukaan isolator ditutupi oleh polutan atau kotoran - kotoran yang mengendap [9]. Udara yang tercemar yang berada di sekitar isolator membawa polutan dan mengendap pada permukaan isolator tersebut [10]. Biasanya, pada musim hujan, material kimia atau polutan yang menempel di permukaan isolator akan larut di permukaan air. Proses pelarutan ini akhirnya membentuk jalur konduktif yang akan menyebabkan arus bocor [10]. Akibatnya adalah permukaan isolator menjadi panas, dan polutan yang terdapat permukaan isolator menjadi kering.

Jika proses ini terus berlanjut, dalam jangka panjang, jalur yang terbentuk akan semakinbersifat konduktif sehingga pada kondisi basah, bahan kimia atau partikel-partikel kontaminan di permukaan isolator akan larut dalam air. Dengan demikian, akan terbentuk jalur konduktif kontiniu baru antara elektroda dan tanah [11]. Selanjutnya tembus permukaan, yaitu kegagalan isolator tidak dapat dibendung, terutama sekali jika terjadi peningkatan proses pelarutan pada partikel-partikel yang berkontaminasi di permukaan isolator dan menyebabkan pembentukan jalur baru [10]. Dengan demikian proses evaluasi tegangan tembus permukaan yang berkontaminasi isolator ini sangat perlu dilakukan. Hal ini penting dilakukan terutama sekali untuk pembuatan isolasi termal pada sistem transmisi tenaga listrik[12].

Penyebab utama terjadinya degradasi dan kegagalan pada isolasi adalah oleh aktivitas korona pada tegangan tinggi; yaitu dalam penerapannya, kondisi lingkungan akan sangat berdampak pada isolator yang terletak diluar ruangan, contohnya adanya dampak pada endapan polutan dan suhu. Akibatnya adalah kemampuan kerja isolator akan menurun atau berada di bawah kemampuan kerja biasanya[13-16].

\section{Metodologi Penelitian}

Penelitian ini merupakan rangkaian dari penelitian sebelumnya dan bagian dari rencana penelitian jangka panjang pengembangan isolasi bahan bionanokomposit untuk aplikasi tegangan tinggi. Untuk keperluan pengujian sifat hidropobisitas dipersiapkan empat buah jenis sampel bionanosilika dengan komposisi LDPE dan NR tetap sebesar 80:20. Sedangkan nanosilika ditambahkan ke sampel LDPE+NR dengan berat berfariasi diberi kode S. Sampel S1 adalah penambahan silika $1.5 \%$ dari total berat LPDE+NR. Begitu juga untuk sampel sampel S2 3\%, sampel S3 silika $4.5 \%$ dan sampel S4 6\%. Total berat sampel dalam satu perlakuan adalah 60 gram dengan berat LDPE adalah 48 gram dan karet alam 12 gram. LDPE, NR dan silika dimasukkan ke dalam ruang pencampuran secara bersamaan yaitu mesin rheomix pada $150^{\circ} \mathrm{C}$ dengan kecepatan putaran rotor 60rpm selama 12 menit. Setelah proses ini selesai, campuran disimpan dalam oven selama 24 jam pada suhu $70^{\circ} \mathrm{C}$. Langkah selanjutnya dari sampel insulasi dicetak menggunakan Hotpress Collin 300p dalam 4 fase.

Diagram alir pengujian hidrofobisitas dapat dilihat pada gambar 1, Selama masa pengujian sampel diletakkan di atas bidang datar sempurna sehingga sudut yang dibentuk antara permukaan dan tetesan air sama di setiap sisi. Dua buah jenis air yaitu air hujan dan air sumur diteteskan di atas permukaan sampel bionanokomposit. Posisi kamera dan sampel membentuk garis lurus. Volume air yang diteteskan adalah $50 \mu$ l. Gambar yang diambil langsung disimpan untuk diukur dan dianalisa sudut kontaknya [10]. Gambar 2 memperlihatkan rangkaian pengujian hidrofobisitas bahan bionanokomposit. Tetesan air diperoleh dengan menggunakan pipet tetes $50 \mu \mathrm{l}$, kamera digital yang digunakan untuk pengambilan gambar, 
lampu $1000 \mathrm{w}$ untuk penerangan saat pengambilan gambar, komputer digunakan untuk menyimpan dan pengolah data kontak pengujian.

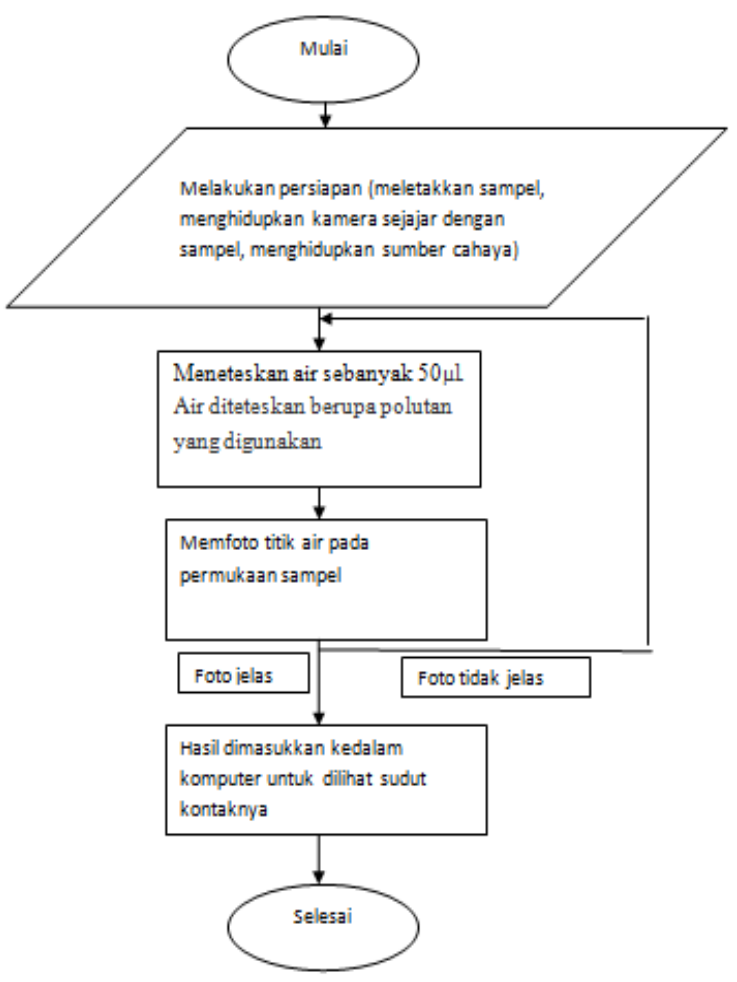

(a)

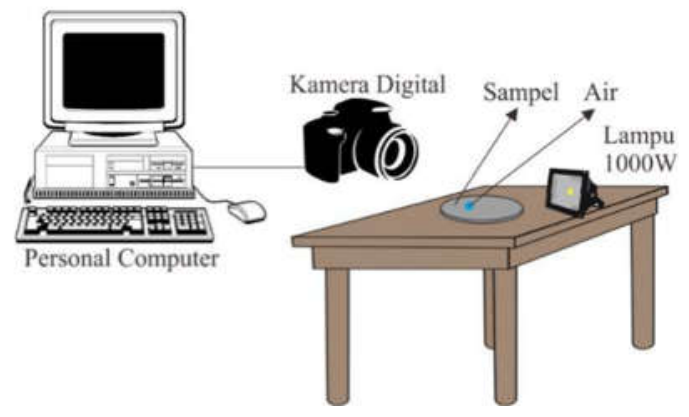

(b)

Gambar 1 Sistem pengujian hidrofobisitas (a) Diagram alir (b) Rangkaian pengujian hidrofobisitas

\section{Hasil dan Pembahasan}

\subsection{Sudut Kontak Air Biasa}

Tabel 1 memperlihatkan detail pengaruh penambahan presentase berat nanopartikel silika terhadap sifat hidropobisitas komposit LDPE-NR pada pengujian dengan air biasa.
Tabel 1 Pengaruh penambahan presentase berat nanopartikel silika terhadap sifat hidropobisitas komposit LDPE-NR pada pengujian dengan air biasa

\begin{tabular}{|c|c|c|c|c|}
\hline $\begin{array}{c}\text { Kode } \\
\text { Sampel }\end{array}$ & $\begin{array}{c}\text { Konsentrasi } \\
\text { Pengisi(\%) }\end{array}$ & $\begin{array}{c}\text { Sudut } \\
\text { Kontak } \\
\text { Kiri }\end{array}$ & $\begin{array}{c}\text { Sudut } \\
\text { Kontak } \\
\text { Kanan }\end{array}$ & $\begin{array}{c}\text { Rata- } \\
\text { rata }\end{array}$ \\
\hline S1 & 1,5 & 84 & 83 & 83,5 \\
\hline S2 & 3 & 91,31 & 89,14 & 91 \\
\hline S3 & 4,5 & 92,17 & 92,2 & 92 \\
\hline S4 & 6 & 95,6 & 94,11 & 95,9 \\
\hline
\end{tabular}

Gambar 2 memperlihat sudut kontak yang terbentuk antara permukaan bionanokomposit dengan kandungan nano silika berbeda ketika ditetesi air biasa. Terlihat adanya peningkatan sudut kontak seiring dengan bertambahnya persentase berat partikel nano silika. Dari keempat sampel yang diujikan, sampel S1 dan S2 membentuk sudut kurang dari $90^{\circ}$. Kandungan persentase berat nano silika adalah 1,5\% dan 3,0\%. Sampel S3 dan S4 dengan kandungan nano silika lebih tinggi membentuk sudut yang lebih besar dari $90^{\circ}$.

Gambar 3 memperlihatkan perubahan sudut kontak antara permukaan bionano komposit setelah ditetesi air biasa. Sudut kontak meningkat dari $83,5^{\circ}$ derjat menjadi $95,9^{\circ}$ akibat penambahan konsenterasi nano silika dari $1,5 \%$ ke $6,0 \%$. Peningkatan ini disebabkan semakin halusnya permukaan isolator bionano komposit seiring bertambahnya jumlah patikel nano silika yang bersifat menolak air.

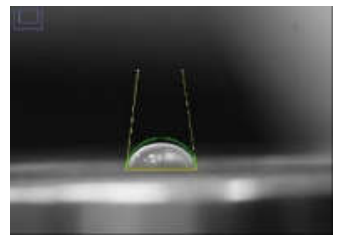

(a)

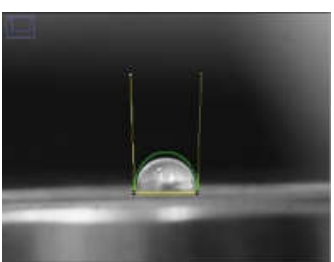

(c)

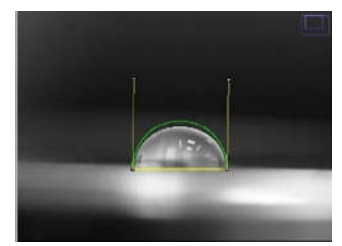

(b)

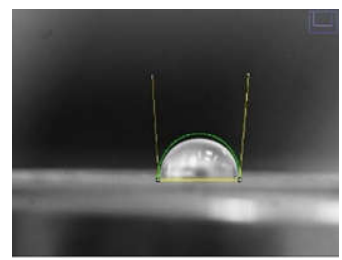

(d)
Gambar 2 Sudut kontak pada permukaan sampel bionanokomposit menggunakan air biasa (a) Sampel S1 (b) Sampel S2 (c) Sampel S3 dan (d) Sampel S4 


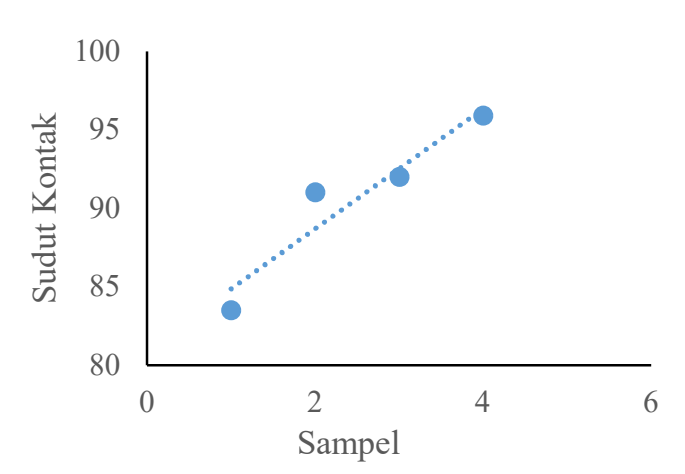

Gambar 3 Pengaruh penambahan presentase berat nanopartikel silika terhadap sifat hidrophobisitas komposit LDPE-NR pada pengujian dengan air biasa

\subsection{Sudut Kontak Air Hujan}

Table 2 memperlihatkan rincian pengaruh penambahan presentase berat nanopartikel silika terhadap sifat hidophobisitas komposit LDPE-NR pada pengujian dengan air hujan. Persentase berat nanosilika tidak memperlihatkan adanya perubahan signifikan pada sudut kontak dan sudut yang dibentuk kecil dari $90^{\circ}$ untuk semua komposisi.

Tabel 2 Pengaruh penambahan presentase berat nanopartikel silika terhadap sifat hidophobisitas komposit LDPE-NR pada pengujian dengan air hujan

\begin{tabular}{|c|c|c|c|c|}
\hline $\begin{array}{c}\text { Kode } \\
\text { Sampel }\end{array}$ & $\begin{array}{c}\text { Konsentrasi } \\
\text { Pengisi(\%) }\end{array}$ & $\begin{array}{c}\text { Sudut } \\
\text { Kontak } \\
\text { Kiri }\end{array}$ & $\begin{array}{c}\text { Sudut } \\
\text { Kontak } \\
\text { Kanan }\end{array}$ & $\begin{array}{c}\text { Rata- } \\
\text { rata }\end{array}$ \\
\hline S1 & 1,5 & 63.43 & 63.56 & 63 \\
\hline S2 & 3 & 67,86 & 67,38 & 67 \\
\hline S3 & 4,5 & 68,7 & 68,4 & 68,5 \\
\hline S4 & 6 & 70 & 70,68 & 70 \\
\hline
\end{tabular}

Gambar 4 memperlihatkan sudut kontak dari sampel S1, S2, S3 dan S4. Semua sudut yang terbentuk kecil dari 90 . Walaupun ada peningkata besar sudut tapi tidak besar. Tren peningkat tersebut dapat dilihat pada gambar 5 yang cendrung linear dan datar. Perubahan sudut yang kecil mengindikasikan bahwa air hujan atau bisa disebut air murni tidak terpengaruh oleh permukaan sampel yang telah mengandung partikel nano silika.

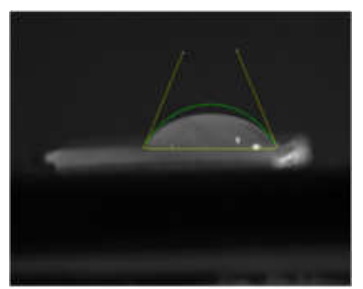

(a)

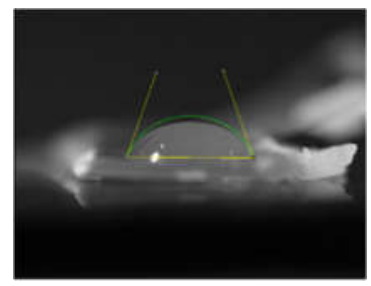

(c)

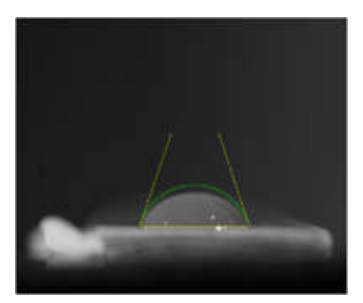

(b)

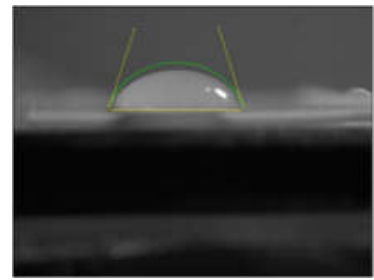

(d)
Gambar 4 Sudut kontak pada permukaan sampel bionanokomposit menggunakan air hujan (a)Sampel S1 (b)Sampel S2 (c)Sampel S3 dan (d) Sampel S4

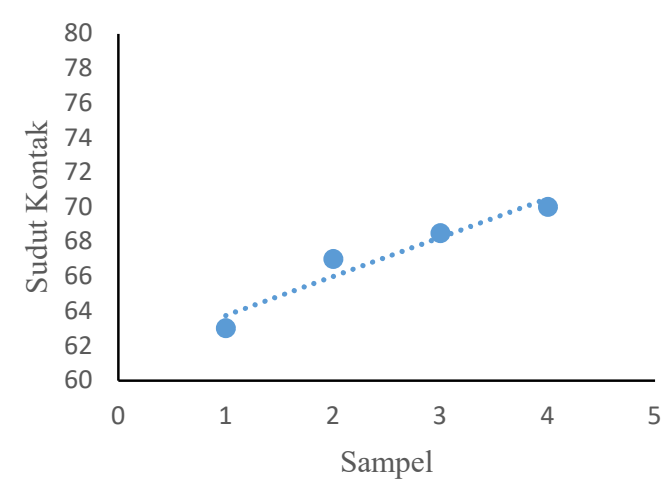

Gambar 5. Pengaruh penambahan presentase berat nanopartikel silika terhadap sifat hidrophobisitas komposit LDPE-NR pada pengujian dengan air hujan

\section{Kesimpulan}

Penelitian telah telah sukses dilakukan dan hasil memperlihatkan bahwa peningkatan persentase nanofiller silika di dalam biokoposit LDPE-NR sebesar 1,5\% menghasilkan sudut kontak sebesar 83,5 pada air biasa dan 63 pada air hujan, sementara penambahan nanofiller silika sebesar 6\% menghasilkan sudut kontak sebesar 95,9 pada air biasa dan 70 pada air hujan. Hasil memberikan informasi bahwa peningkatan konsentrasi nanofiller silika dapat meningkatkan sudut kontak yang mencerminkan peningkatan sifat tolak air. 


\section{Ucapan Terima Kasih}

Penulis mengucapkan terima kepada Jurusan Teknik Elektro yang telah mendanai penelitian ini pada tahun 2019.

\section{Daftar Pustaka}

[1] A. Abedini-Livari, M. Eshaghi-Maskouni, M. Vakilian, and K. Firuzi, "Line Composite Insulators Condition Monitoring through Partial Discharge Measurement," in 2019 International Power System Conference (PSC), 2019, pp. 595-600.

[2] Y. Sun, Y. Yi, and L. Wang, "Study on Formulation and Hydrophobicity of Polyurethane Filled with DC Post Insulators," in 2018 2nd IEEE Conference on Energy Internet and Energy System Integration (EI2), 2018, pp. 1-4.

[3] X. Huang, H. Gao, W. Cao, Y. Tian, W. Yang, and Z. Yuan, "Study on Ultraviolet Aging Properties of High Polymer Composite Insulators," in 2018 Condition Monitoring and Diagnosis (CMD), 2018, pp. 1-5.

[4] R. Samet and M. Tanriverdi, "Face Recognition-Based Mobile Automatic Classroom Attendance Management System," in 2017 International Conference on Cyberworlds (CW), 2017, pp. 253-256.

[5] D. Yang, Y. Ni, X. Kong, H. Xue, W. Guo, and L. Zhang, "Enhanced electromechanical properties of natural rubber using highly efficient and cost-effective mussel-inspired modification of TiO2 nanoparticles," Applied Surface Science, vol. 495, p. 143638, 2019/11/30/ 2019.

[6] S. Dong, S. Sapieha, and H. P. Schreiber, "Mechanical-Properties of Corona-Modified Cellulose Polyethylene Composites," (in English), Polymer Engineering and Science, vol. 33, no. 6, pp. 343-346, Mar 1993.

[7] Y. Z. Arief et al., "Effects of nanosilica and nanotitania on partial discharge characteristics of natural rubber-lldpe blends as high voltage insulation material," in Electrical Insulating Materials (ISEIM), Proceedings of 2014 International Symposium on, 2014, pp. 299302.

[8] M. Z. H. Makmud, Aulia, Y. Z. Arief, and M. U. Wahit, "Ageing and degradation mechanism of linear low density polyethylenenatural rubber composites due to partial discharge," in PECon 2012 - 2012 IEEE
International Conference on Power and Energy, 2012, pp. 985-989.

[9] Aji Suryo Alam, Achmad Solichan dan Agung Nugroho, 2013, Analisa Pengaruh Variasi dan Komposisi Bahan Pengisi Terhadap Unjuk Kerja Sampel Isolator Resin Epoksi Silane, Jurnal Transient, VOL.2, NO. 3.

[10] Moh. Toni Prasetyo1, Achmad Solichan, 2014., Efektifitas Pemanfaatan Pasir Pantai Berkalsium Sebagai Material Pengisi Bahan Isolasi Resin Epoksi Untuk Isolator Listrik.

[11] Anhar Ashari, A.S., and Bambang Winardi, Analisa Pengaruh Kontaminan Pantai Terhadap Unjuk Kerja Sampel Isolator Bahan Keramik Sebelum dan Sesudah Dilapisi Minyak Silikon. 2012

[12] Basanta Kumar Gautam, T.Y., Kazuma Yamada, Shuhei Matsushita, Kenji Sakanishi and Ryosuke Matsuoka, Effect of Non-soluble Contaminants on The Flashover Voltages of Hydrophobic Polymer Insulators. 2006

[13] M.Putra Nurjanah, F., Analisis Pengaruh Endapan Polutan dengan Metode Equivalent Salt Deposit Density (ESDD) terhadap Tegangan Korona pada Isolator Pin Post di Jaringan Distribusi $20 \quad \mathrm{kV}$ Pekanbaru.JOMTeknik, 2016. vol.3.

[14] Syakur, A., et al., Analisis Sifat Hidrofobik Permukaan Hdpe Berdasarkan Nilai Total Harmonic Distortion. TELKOMNIKA (Telecommunication Computing Electronics and Control), 2009. 7(2): p. 109.

[15] Shirazi, M.M.S., H. Borsi, and E. Gockenbach. Effect of TiO2 nanofillers on electrical, thermal and mechanical parameters of epoxy resin. in 2012 IEEE International Symposium on Electrical Insulation. 2012.

[16] Setiawan, M.H., Reparasi Sampel dan Pengujian Tensile Strength Isolasi Nanokomposit di Pusat Teknologi Material (PTM-BPPT). 2018 